Article

\title{
The Preventive and Curative Effects of Lactobacillus reuteri NK33 and Bifidobacterium adolescentis NK98 on Immobilization Stress-Induced Anxiety/Depression and Colitis in Mice
}

\author{
Hyo-Min Jang ${ }^{\dagger}$, Kyung-Eon Lee $^{\dagger}$ and Dong-Hyun Kim $*$ (D) \\ Neurobiota Research Center, Department of Life and Nanopharmaceutical Sciences, College of Pharmacy, \\ Kyung Hee University, Kyungheedae-ro, Dongdaemun-gu, Seoul 02447, Korea; jhm0346@naver.com (H.-M.J.); \\ mljun@nate.com (K.-E.L.) \\ * Correspondence: dhkim@khu.ac.kr; Tel.: +82-2-961-0374 \\ + These authors contributed equally to this work as first authors.
}

Received: 4 March 2019; Accepted: 9 April 2019; Published: 11 April 2019

\begin{abstract}
The gut dysbiosis by stressors such as immobilization deteriorates psychiatric disorders through microbiota-gut-brain axis activation. To understand whether probiotics could simultaneously alleviate anxiety/depression and colitis, we examined their effects on immobilization stress (IS)-induced anxiety/depression and colitis in mice. The probiotics Lactobacillus reuteri NK33 and Bifidobacterium adolescentis NK98 were isolated from healthy human feces. Mice with anxiety/depression and colitis were prepared by IS treatment. NK33 and NK98 potently suppressed NF- $\mathrm{kB}$ activation in lipopolysaccharide (LPS)-induced BV-2 cells. Treatment with NK33 and/or NK98, which were orally gavaged in mice before or after IS treatment, significantly suppressed the occurrence and development of anxiety/depression, infiltration of $\mathrm{Iba}^{+}$and $\mathrm{LPS}^{+} / \mathrm{CD} 11 \mathrm{~b}^{+}$cells (activated microglia) into the hippocampus, and corticosterone, IL-6, and LPS levels in the blood. Furthermore, they induced hippocampal BDNF expression while NF- $\mathrm{kB}$ activation was suppressed. NK33 and/or NK98 treatments suppressed IS-induced colon shortening, myeloperoxidase activity, infiltration of $\mathrm{CD} 11 \mathrm{~b}^{+} / \mathrm{CD} 11 \mathrm{c}^{+}$cells, and IL-6 expression in the colon. Their treatments also suppressed the IS-induced fecal Proteobacteria population and excessive LPS production. They also induced BDNF expression in LPS-induced SH-SY5Y cells in vitro. In conclusion, NK33 and NK98 synergistically alleviated the occurrence and development of anxiety/depression and colitis through the regulation of gut immune responses and microbiota composition.
\end{abstract}

Keywords: Bifidobacterium adolescentis; Lactobacillus reuteri; depression; anxiety; immobilization stress; colitis

\section{Introduction}

Anxiety disorder is the most common disorder characterized by somatic, emotional, cognitive, and behavioral components [1,2]. Patients with anxiety disorders progress to the depressive disorder that is a common illness worldwide [3]. Anxiety/depression was approximated in experimental rodents by treating stressors such as immobilization and forced swimming [4,5]. Exposure to stressors induces the secretion of adrenaline, noradrenaline, and glucocorticoids from the adrenal gland through the hypothalamic-pituitary-adrenal (HPA) axis activation, regulates the expression of proinflammatory cytokines such as tumor necrosis factor (TNF)- $\alpha$ and interleukin (IL)- 6 in immune cells, shifts gut microbiota composition, and increases gut bacterial lipopolysaccharide (LPS) production [6-8]. However, 
the up-regulation of these proinflammatory cytokines suppresses the brain-derived neurotrophic factor (BDNF) expression in the hippocampus [8,9].

Gut microbiota consists of greater than 1000 species from relatively few phyla including Firmicutes, Bacteroidetes, and Proteobacteria [10,11]. Although the gut microbiota composition is inter-individually variable and changeable, a number of their functions for maintaining health status are associated with the core microbiota [11,12]. The gut microbiota and their byproducts stimulate enteric nervous and immune systems in the gastrointestinal tract, which propagates into other organs in the body by regulating the secretion of cytokines and adrenal hormones [13-15]. The occurrence of gut microbiota dysbiosis by stressors can disturb the host homeostasis, resulting in systemic disorders such as anxiety and depression [15-17]. Germ-free mice exhibit the severe anxiety-like behaviors compared with conventional mice [18]. However, the fecal transplantation of conventional mice into germ-free mice suppresses anxiety [19]. Thus, the brain can regulate gut function and microbiota composition through the nervous and immune systems, namely HPA axis, and the gut microbiota can regulate the psychiatric function through endocrine, neural, and immune responses, namely microbiota-gut-brain (MGB) axis $[20,21]$. Therefore, regulating the MGB axis is useful for the therapy of psychiatric disorders.

Probiotics, including bifidobacteria and lactobacilli, exhibit a variety of pharmacological activities: They alleviate constipation, diarrhea, imbalanced immune system, and psychiatric disorders [22,23]. Lactobacillus plantarum, which is isolated from zebrafish, attenuates anxiety in zebrafish [24]. Lactobacillus reuteri, which is isolated from mice, alleviates anxiety in mice [25]. Bifidobacterium adolescentis IM38, which is isolated from human gut microbiota, alleviates IS-induced anxiety in mice [26]. Nevertheless, the anti-depressive mechanism of probiotics is still unclear.

Therefore, we isolated commensal Lactobacillus reuteri NK33 and Bifidobacterium adolescentis NK98 from healthy human feces and investigated their preventive and curative effects on immobilization stress (IS)-induced anxiety/depression and colitis in mice.

\section{Materials and Methods}

\subsection{Materials}

Dulbecco Modified Eagle Medium (DMEM) and corticosterone were purchased from Sigma (St. Louis, MO, USA). Antibodies were purchased from Cell Signaling Technology (Beverly, MA, USA). Enzyme-linked immunosorbent assay (ELISA) kits for corticosterone (E-EL-M0349) and IL-6 were purchased from Elabscience (Hebei, China) and eBioscience (San Diego, CA, USA), respectively.

\subsection{Culture of Lactobacillus reuteri NK33 and Bifidobacterium adolescentis NK98 and Their Dosage Regimen}

Lactobacillus reuteri NK33 and Bifidobacterium adolescentis NK98 were isolated from fresh human feces and identified, as previously reported [26] and deposited in the Korea Culture Center for Microorganisms (KCCM 12297 and KCTC12090). Isolated probiotics were cultured in general media for probiotics such as De Man, Rogosa and Sharpe (MRS) broth (Becton, Dickinson and Company, Radnor, PA, USA). Cultured cells were centrifuged $\left(5000 \times g, 20 \mathrm{~min}, 20^{\circ} \mathrm{C}\right)$, washed with saline, and suspended in saline (for in vitro experiments) or $1 \%$ maltose (for in vivo experiments).

To decide the dose of NK33 and NK98 in mouse experiments, they $\left(1 \times 10^{7}, 1 \times 10^{8}\right.$, and $1 \times 10^{9} \mathrm{CFU} /$ mouse/day) were orally given for 5 days in IS-treated mice and their anti-depressive effects were evaluated in the elevated plus maze task, as previously reported [25]. Among these, treatment with NK33 or NK98 at a dose of $1 \times 10^{9} \mathrm{CFU} /$ mouse/day strongly alleviated IS-induced anxiety-like behaviors. Therefore, we orally gavaged NK3 or NK49 at a dose of $1 \times 10^{9} \mathrm{CFU} / \mathrm{mouse} /$ day for the further in vivo study.

\subsection{Culture of BV2 and SH-SY5Y Cells}

Human neuroblastoma SH-SY5Y and murine microglial BV-2 cells (Korea Cell Line Bank, Seoul, Korea) were cultured at $37{ }^{\circ} \mathrm{C}$ in a $95 \%$ air $/ 5 \% \mathrm{CO}_{2}$ atmosphere in DMEM containing $5 \%$ fetal 
bovine serum and 1\% antibiotic-antimycotic [27]. For the assay of BDNF expression, SH-SY5Y cells $\left(1 \times 10^{6}\right.$ cells $\left./ \mathrm{mL}\right)$ were incubated with LPS $(100 \mathrm{ng} / \mathrm{mL}$, purified from Escherichia coli O111:B4, Sigma) in the absence or presence of test probiotics for $24 \mathrm{~h}$. For the assay of IL- 6 expression and NF- $k B$ activation, BV-2 cells $\left(1 \times 10^{6}\right.$ cells $\left./ \mathrm{mL}\right)$ were incubated with LPS $(100 \mathrm{ng} / \mathrm{mL})$ in the absence or presence of test probiotics for $1.5 \mathrm{~h}$ (for NF- $\mathrm{kB}$ activation) or $20 \mathrm{~h}$ (for IL-6 expression). Protein expression levels were assayed by immunoblotting and ELISA.

\subsection{Animals}

C57BL/6 mice (male, 5 weeks old, 19-21 g) were supplied from Orient Bio (Seongnam-shi, Korea) and adapted for 7 days before experiments. All animals were maintained in wire cages under standard conditions of constant temperature $\left(20 \pm 2{ }^{\circ} \mathrm{C}\right)$, humidity $(50 \% \pm 10 \%)$ and lighting $(12 \mathrm{~h} /$ day $)$. All mice were fed standard laboratory chow and tap water ad libitum.

Animal experiments were conducted according to the National Institute of Health (NIH) and University Guide for Laboratory Animal Care and Usage. All animal experimental procedures were approved by the Institutional Animal Care and Use Committee of the University (IACUC No KUASP(SE)-17-146-1).

\subsection{Preparation of Mice with Anxiety/Depression and Colitis}

To examine the curative effects of probiotics on anxiety/depression, mice were randomly assigned to six groups (NC, C, PC, NK33, NK98, or Mix) of seven mice each. First, mice from the PC, NK33, NK98, Mix, and C groups were exposed to IS and test agents (C, vehicle [1\% maltose]; NK33, $1 \times 10^{9} \mathrm{CFU} / \mathrm{mouse} /$ day of NK33; NK98, $1 \times 10^{9} \mathrm{CFU} / \mathrm{mouse} /$ day of NK98; Mix, $1 \times 10^{9} \mathrm{CFU} / \mathrm{mouse} /$ day of the (1:1) mixture of NK33 and NK98]; and PC, $1 \mathrm{mg} / \mathrm{kg} /$ day of buspirone) either orally (for NK33, NK98, and Mix) or intraperitoneally (for buspirone) administered for 5 days, $24 \mathrm{~h}$ after the final treatment with IS. The normal control group (NC), not exposed to IS, was treated with $1 \%$ maltose in place of test agents. Behaviors and biochemical markers were assayed $20 \mathrm{~h}$ after the final treatment. Exposure of mice to IS was performed for $12 \mathrm{~h}$ once a day for 2 days using a conical tube-like instrument $(2.5 \mathrm{~cm}$ in diameter, $7.5 \mathrm{~cm}$ in length) with a 0.25 - $\mathrm{cm}$-diameter hole on the center of the tube), as previously reported $[25,28]$.

To examine the preventive effects of probiotics on anxiety/depression and colitis, mice were randomly assigned to six groups of seven mice each. First, test agents $(C$, vehicle [1\% maltose]; NK33, $1 \times 10^{9} \mathrm{CFU} / \mathrm{mouse} /$ day of NK33; NK98, $1 \times 10^{9} \mathrm{CFU} / \mathrm{mouse} /$ day of NK33; Mix, $1 \times 10^{9} \mathrm{CFU} / \mathrm{mouse} /$ day of the (1:1) mixture of NK33 and NK98]; and PC, $1 \mathrm{mg} / \mathrm{kg} /$ day of buspirone) were orally gavaged or intraperitoneally injected into the mice daily for 5 days. Mice from the PC, NK33, NK98, Mix, and C groups were exposed to IS for $2 \mathrm{~h}$ from $24 \mathrm{~h}$ after the final treatment with test agents, as previously reported [28]. Normal control group (NC), not exposed to IS, was orally treated with $1 \%$ maltose in place of test agents. Behaviors and biochemical markers were assayed $20 \mathrm{~h}$ after the final IS treatment.

\subsection{Behavioral Tasks}

The elevated plus maze task was carried out in the plus-maze apparatus, which consisted of two open $(30 \mathrm{~cm} \times 7 \mathrm{~cm})$ and two enclosed arms $(30 \times 7 \mathrm{~cm})$ with 20-cm-high walls extending from a central platform $(7 \mathrm{~cm} \times 7 \mathrm{~cm})$ on a single central support to a height of $60 \mathrm{~cm}$ above the floor for $5 \mathrm{~min}$, as previously reported [25]. The light/dark transition task was carried out in the light/dark box apparatus $(45 \mathrm{~cm} \times 25 \mathrm{~cm} \times 25 \mathrm{~cm})$, which consisted of two chambers (black and white polywoods [walls] and Plexiglass [floor] connected by an opening $(7.5 \mathrm{~cm} \times 7.5 \mathrm{~cm})$ located at floor level in the center of the dividing wall) for $5 \mathrm{~min}$, as previously reported [25]. A tail suspension test (TST) was measured according to the method of Dunn and Swiergiel [29]. Mice were suspended on the edge of a table $30 \mathrm{~cm}$ above the floor by taping $1 \mathrm{~cm}$ from the tail tip. Immobility time was measured for $5 \mathrm{~min}$. When the mice did not move and passively hung, mice were judged to be immobile. A forced swimming test (FST) was performed in a round transparent plastic jar $(20 \mathrm{~cm} \times 40 \mathrm{~cm})$ containing fresh 
water $\left(25^{\circ} \mathrm{C}\right)$ of $25 \mathrm{~cm}$ height according to the method of Dunn and Swiergiel [29]. Immobility time was measured for $5 \mathrm{~min}$. When the mice remained floating in the water without movement, mice were judged to be immobile.

\subsection{Immunobloting and ELISA}

Hippocampus, colon tissues, SH-SY5Y, and BV2 cells were lysed with lysis RIPA buffer, which contained $1 \%$ phosphatase and protease inhibitor cocktails and centrifuged $(10,000 \times g, 10 \mathrm{~min}$, $4{ }^{\circ} \mathrm{C}$ ) [30]. For the ELISA, the supernatants of the hippocampus and colon tissues, cultured cells, and blood, which was centrifuged $\left(3000 \times g, 5 \mathrm{~min}, 4^{\circ} \mathrm{C}\right)$, were transferred to a 96-well plate. Corticosterone and cytokine concentrations were assayed using their ELISA kits. For the immunoblotting analysis, the supernatant (proteins) was electrophoresed, as previously reported [30]. Electrophoresed proteins were transferred to a membrane, blocked with 5\% non-fat dried-milk proteins, and probed with the corresponding antibodies. The membrane was incubated with horseradish peroxidase-conjugated secondary antibodies. Proteins were visualized with an enhanced chemiluminescence detection kit.

\subsection{Immunofluorescence Assay}

The immunofluorescence assays of brains and colons were performed, as previously reported [30]. Briefly, mice were transcardiacally perfused with $4 \%$ paraformaldehyde. Brains and colons were removed, fixed with $4 \%$ paraformaldehyde for $4 \mathrm{~h}$, cytoprotected in a $30 \%$ sucrose solution, and frozen. The frozen tissues were cut using a cryostat, incubated for $16 \mathrm{~h}$ at $4{ }^{\circ} \mathrm{C}$ with the Iba1 antibody for microglia, LPS and CD11b antibodies for $\mathrm{LPS}^{+} / \mathrm{CD}_{11}{ }^{+}$cells (activated microglia), and CD11b and CD11c antibodies for CD11b ${ }^{+} / \mathrm{CD}_{11} \mathrm{c}^{+}$cells (dendritic cells and macrophages), and incubated with Alexa Fluor 488 (1:1000, Invitrogen, Carlsbad, CA, USA) or Alexa Fluor 594 (1:500, Abcam, Cambridge, UK) conjugated secondary antibodies. The nuclei staining was performed using 4',6-diamidino-2-phenylindole (DAPI). The immunostained sections were observed using a confocal laser microscope.

\subsection{Quantitative Polymerase Chain Reaction ( $q P C R$ )}

To analyze fecal microbiota, total DNA $(0.1 \mu \mathrm{g})$ was isolated from mouse feces and qPCR was carried out with SYBER premix in a Takara thermal cycler, as previously reported [30]. The thermal cycling condition was as follows: Initial denaturation was $95^{\circ} \mathrm{C}$ for $30 \mathrm{~s}$; cycling, $43 \mathrm{~s}$; denaturation, $95^{\circ} \mathrm{C}$ for $5 \mathrm{~s}$; annealing, $63{ }^{\circ} \mathrm{C}$ for $30 \mathrm{~s}$; and extension, $72{ }^{\circ} \mathrm{C}$ for $30 \mathrm{~s}$. The bacterial population level was calculated relative to $16 \mathrm{~S}$ ribosomal RNA by using Microsoft Excel (Microsoft, Redmond, WA, USA). Abundance (\%) was [each bacterial population in each feces]/[each bacterial population in the highest one] $\times 100$. Primers are indicated in Table 1 .

Table 1. Primers used in the present experiments.

\begin{tabular}{|c|c|c|}
\hline \multirow{2}{*}{ Phylum } & \multicolumn{2}{|c|}{ Primer Sequence } \\
\hline & Forward & Reverse \\
\hline Firmicutes & 5'-GGAGYATGTGGTTTAATTCGAAGCA-3' & 5'-AGCTGACGACAACCATGCAC-3' \\
\hline Bacteroidetes & 5'-GTTTAATTCGATGATACGCGAG-3' & 5'-TTAASCCGACACCTCACGG-3' \\
\hline Actinobacteria & 5'-TGTAGCGGTGGAATGCGC-3' & 5'-AATTAAGCCACATGCTCCGCT-3' \\
\hline$\delta / \gamma$-Proteobacteria & 5'-GCTAACGCATTAAGTRYCCCG-3' & 5'-GCCATGCRGCACCTGTCT-3' \\
\hline \multirow{2}{*}{ 16S rRNA } & 5'-TCGTCGGCAGCGTCAGATGTGTATAA & 5'-GTCTCGTGGGCTCGGAGATGTGTATA \\
\hline & GAGACAGGTGCCAGCMGCCGCGGTAA-3' & AGAGACAGGGACTACHVGGGTWTCTAAT-3' \\
\hline
\end{tabular}

\subsection{Limulus Amoebocyte Lysate Assay}

The endotoxin concentrations of feces and blood were assayed, as previously reported [31]. Briefly, mouse fresh feces $(20 \mathrm{mg})$ were suspended in sterilized saline $(30 \mathrm{~mL})$, sonicated for $30 \mathrm{~min}$ at $4^{\circ} \mathrm{C}$, centrifuged $\left(400 \times g, 15 \mathrm{~min}, 4^{\circ} \mathrm{C}\right)$, and sequentially filtrated through $0.45 \mu \mathrm{m}$ and $0.22 \mu \mathrm{m}$ membrane filters. The filtrated solution was heated for $10 \mathrm{~min}$ at $70^{\circ} \mathrm{C}$. Mouse bloods were centrifuged $(3000 \times g$, 
$\left.5 \mathrm{~min}, 4^{\circ} \mathrm{C}\right)$. The plasma was diluted 10 -fold, heated at $70{ }^{\circ} \mathrm{C}$ for $10 \mathrm{~min}$, and centrifuged $(3000 \times \mathrm{g}$, $10 \mathrm{~min}, 20^{\circ} \mathrm{C}$ ). Their endotoxin concentrations were assayed using a LAL assay kit (Cape Cod Inc., East Falmouth, MA, USA).

\subsection{Statistical Analysis}

All experimental values are indicated as the mean \pm standard error of mean (SEM). Their significant differences were analyzed using a one-way analysis of variance (ANOVA) followed by a Duncan multiple range test $(p<0.05)$.

\section{Results}

\subsection{The Curative Effects of NK33 and NK98 against IS-Induced Anxiety/Depression and Colitis in Mice}

In order to investigate whether probiotics arising from the human gut microbiota could simultaneously alleviate anxiety/depression and colitis, we first isolated probiotics from human feces and examined their anti-inflammatory activities in LPS-treated BV-2 cells. Of tested probiotics, NK33 and NK98 strongly inhibited NF- $\mathrm{kB}$ activation and IL-6 expression in LPS-treated BV-2 cells (Figure 1). These probiotics were identified as Lactobacillus reuteri and Bifidobacterium adolescentis, based on the results of Gram staining, API 50 CHL kit (BNFKorea, Seoul, Korea), and 16S rDNA sequencing, respectively.

(A)

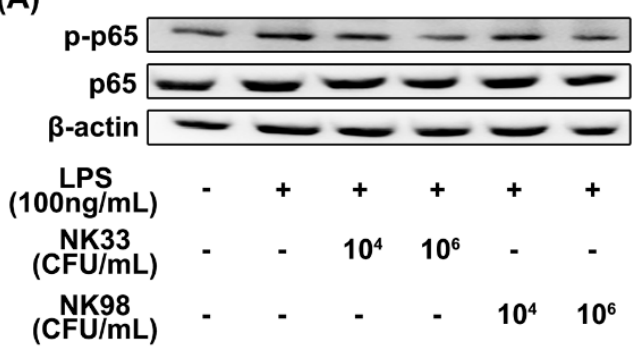

(B)

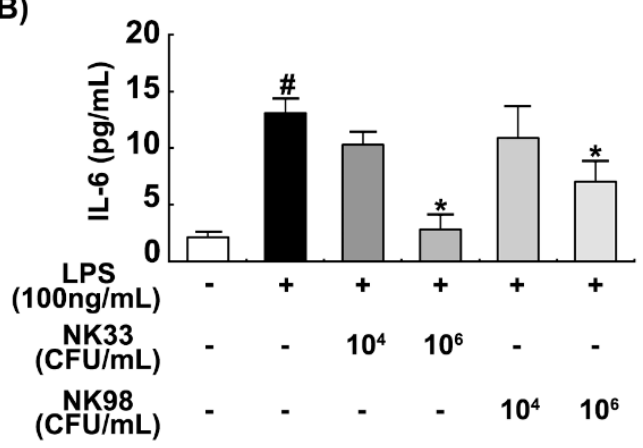

Figure 1. Lactobacillus reuteri NK33 and Bifidobacterium adolescentis NK98 inhibited NF- $\mathrm{KB}$ activation (A) and IL-6 expression in LPS-treated BV-2 cells $\left(\right.$ B). Cells $\left(1 \times 10^{6} / \mathrm{mL}\right)$ were incubated with NK33 or NK98 $\left(1 \times 10^{4}\right.$ or $1 \times 10^{6} \mathrm{CFU} / \mathrm{mL}$ ) in the presence of LPS for $90 \mathrm{~min}$ (for NF-kB) or $20 \mathrm{~h}$ (for IL-6). IL-6 was measured with an ELISA kit. p-p65 and p65 (NF- $\mathrm{kB}$ ) were measured by immunoblotting. Data values are indicated as mean \pm standard error of mean (SEM) $(n=4) .{ }^{\#} p<0.05$ vs. group not treated with LPS; ${ }^{*} p<0.05$ vs. LPS alone treated group. LPS, lipopolysaccharide.

Next, we examined whether NK33 and NK98 could alleviate IS-induced anxiety/depression in mice. Exposure to IS significantly decreased the time spent in open arms (OT) and open arm entries $(\mathrm{OE})$ during the elevated plus maze task to $37.3 \%[\mathrm{~F}(1,12)=22.058, p<0.05]$ and $73.0 \%[\mathrm{~F}(1,12)=10.052$, $p<0.05$ ] of control mice, respectively (Figure 2A,B). Furthermore, IS exposure suppressed the time spent in the light compartment (TL) and number of transitions into the light dark compartment (NT) in the light/dark transition task and increased immobility in the tail suspension and forced swimming tasks. However, oral administration of NK33 or NK98 significantly mitigated OT in the elevated plus maze task to $114.8 \%[\mathrm{~F}(1,12)=16.694, p<0.05]$ and $107.0 \%[\mathrm{~F}(1,12)=23.163, p<0.001]$ of control mice, respectively, $\mathrm{OE}$ in the elevated plus maze task to $99.2 \%[\mathrm{~F}(1,12)=7.670, p<0.05]$ and $93.2 \%$ $[\mathrm{F}(1,12)=5.243, p<0.05]$ of control mice, respectively and TL in the light/dark transition task to $89.5 \%$ $[\mathrm{F}(1,12)=8.856, p<0.05]$ and $81.0 \%[\mathrm{~F}(1,12)=4.956, p<0.05]$ of control mice, respectively. NK33 and NK98 treatment suppressed immobility in the forced swimming task to $80.2 \%[\mathrm{~F}(1,12)=6.951, p<0.05]$ and $81.6 \%[\mathrm{~F}(1,12)=6.214, p<0.05]$ of mice treated with IS alone, respectively, and immobility in 
the tail suspension task to $67.3 \%[\mathrm{~F}(1,12)=4.578, p=0.054]$ and $80.59 \%[\mathrm{~F}(1,12)=15.222, p<0.05]$ of mice treated with IS alone, respectively, while NT in the light/dark transition task was not significantly influenced (Figure 2C-E). Treatment with Mix, the mixture of NK33 and NK98, also additively or synergistically alleviated anxiety/depression-like behaviors. IS exposure also inhibited hippocampal BDNF expression and CREB phosphorylation and increased hippocampal NF- $\mathrm{kB}$ activation (Figure $2 \mathrm{~F}$ ). Furthermore, IS exposure increased the infiltration of activated microglial cells into the hippocampus: It increased Iba $1^{+}$and $\mathrm{LPS}^{+} / \mathrm{CD} 11 b^{+}$cells in the hippocampus (Figure $2 \mathrm{G}, \mathrm{H}$ ). However, treatment with NK33, NK98, or Mix inhibited the NF-KB activation and activated microglial cell infiltration into the hippocampus and induced hippocampal BDNF expression and CREB phosphorylation in IS-exposed mice (Figure 2F). IS exposure also increased blood corticosterone, IL-6, and LPS levels (Figure 2I-K). NK33, NK98, or Mix treatment reduced IS-induced IL-6, corticosterone, and LPS levels.

IS exposure significantly caused colitis in mice. Thus, treatment with IS caused colon shortening and induced colonic myeloperoxidase activity and NF- $\mathrm{kB}$ activation (Figure $3 \mathrm{~A}-\mathrm{F}$ ). Furthermore, treatment with IS significantly increased the $\mathrm{CD} 11 \mathrm{~b}^{+}$and/or $\mathrm{CD} 11 \mathrm{c}^{+}$cell (DCs and macrophages) infiltration into the colon (Figure 3G). Treatment with NK33, NK98, or Mix significantly alleviated IS-induced colon shortening and macroscopic score and suppressed myeloperoxidase activity, IL-6, IL-1 $\beta$, and COX-2 expression, NF- $\mathrm{kB}$ activation, and CD11 $\mathrm{b}^{+}$and/or CD11 $\mathrm{c}^{+}$cell infiltration: They synergistically suppressed IL- $1 \beta$ expression, myeloperoxidase activity, and $C D 11 b^{+} / C D 11 c^{+}$cell infiltration. Furthermore, IS exposure increased the population of Proteobacteria and reduced the populations of Firmicutes and Actinobacteria in the fecal microbiota. However, NK33, NK98, or Mix treatment increased IS-suppressed Bacteroidetes, Firmicutes, and Actinobacteria populations and suppressed IS-induced Proteobacteria population (Figure 3H). Furthermore, they also inhibited the fecal LPS level production in IS-induced mice (Figure 3I). 
(A)
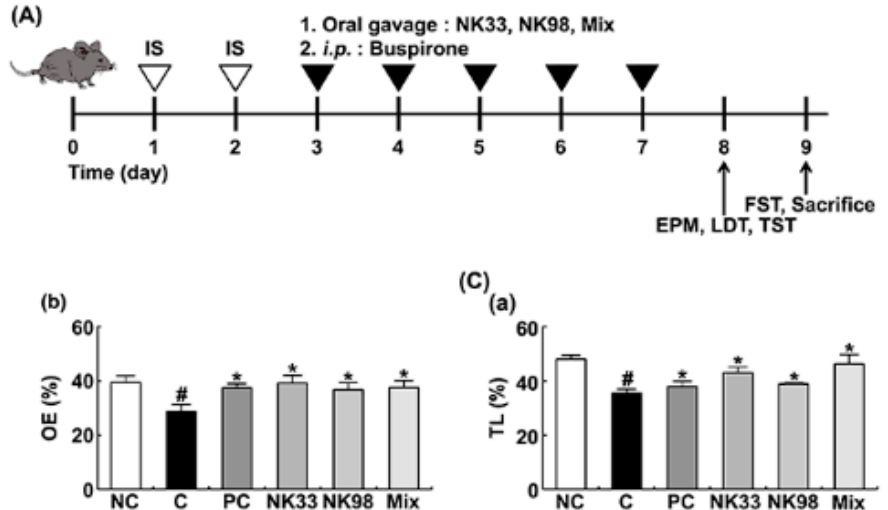

(D)

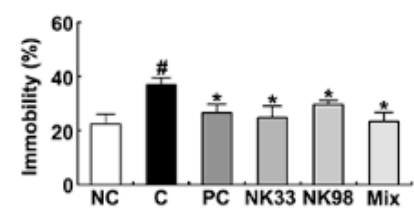

(G)

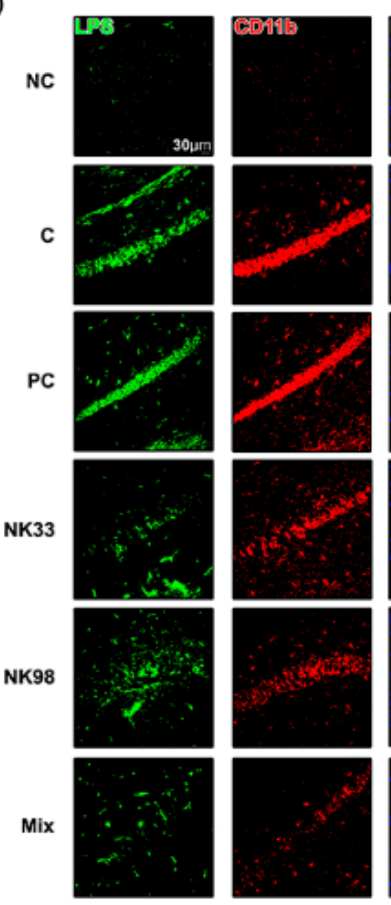

(I)

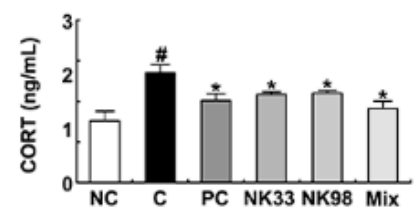

(C)

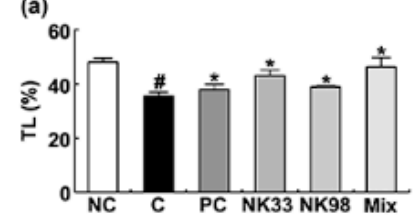

(E)

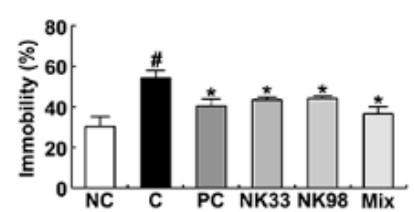

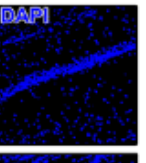
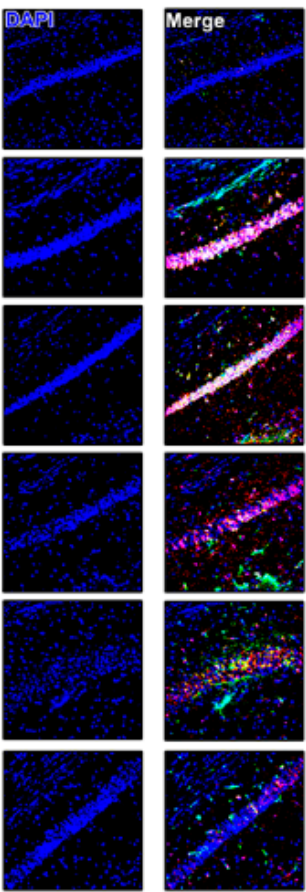

(J)

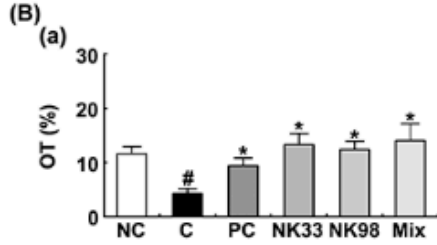

(b)

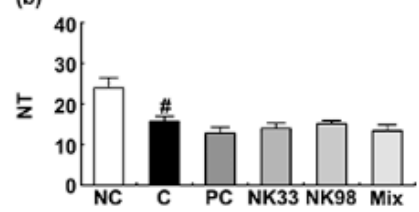

(F)

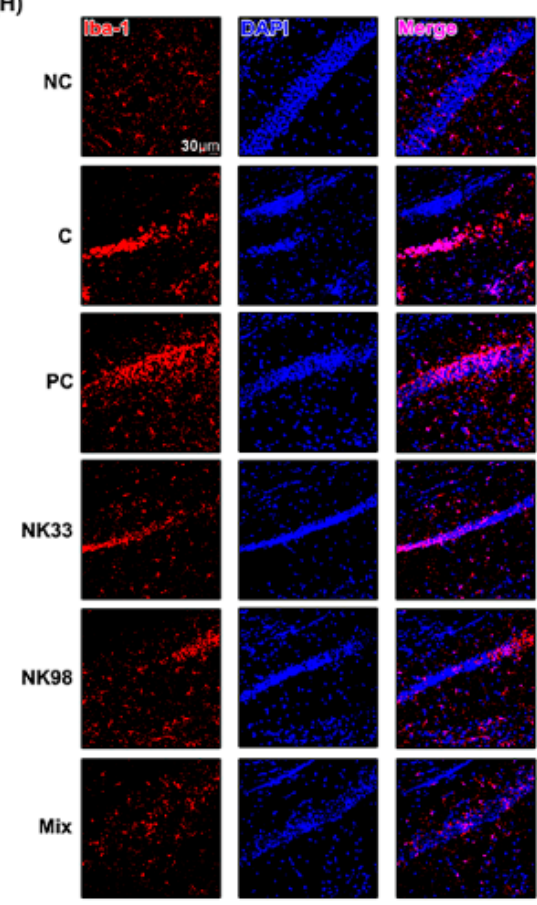

(K)

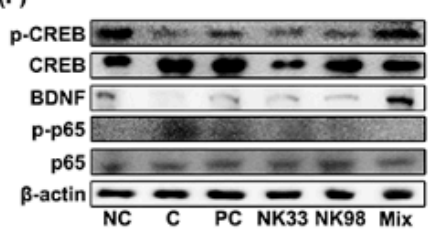

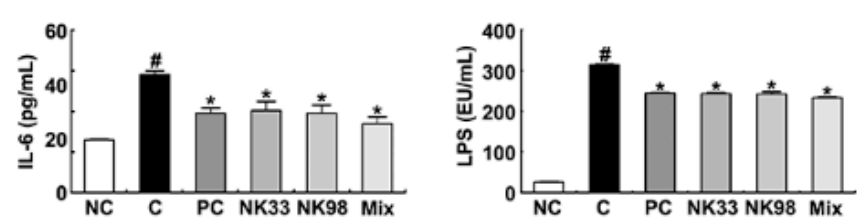

Figure 2. Oral administration of Lactobacillus reuteri NK33 and/or Bifidobacterium adolescentis NK98 attenuated IS-induced anxiety/depression and hippocampal inflammation in mice. (A) Procedure. Effects on anxiety/depression-like behaviors in elevated plus maze (B: (a), OT; (b), OE), LDT (C: (a), TL; (b), NT), tail suspension (D), and forced swimming (E) tasks. (F) Effects on hippocampal BDNF expression, and CREB and NF-KB activation. Effects on the infiltration of $\mathrm{LPS}^{+} / \mathrm{CD} 11 \mathrm{~b}^{+}(\mathbf{G})$ and $\mathrm{Iba}^{+}$ cells $(\mathbf{H})$ into the hippocampus. Effects on blood corticosterone (CORT, I), IL-6 (J), and LPS levels (K). Mice were exposed to IS and test agents (C, vehicle [ $1 \%$ maltose]; NK33, $1 \times 10^{9} \mathrm{CFU} /$ mouse/day of 
NK33; NK98, $1 \times 10^{9} \mathrm{CFU} / \mathrm{mouse} /$ day of NK33; Mix, $1 \times 10^{9} \mathrm{CFU} / \mathrm{mouse} /$ day of the (1:1) mixture of NK33 and NK98]; and PC, $1 \mathrm{mg} / \mathrm{kg} /$ day of buspirone) were gavaged (for vehicle, NK33, and NK98) or intraperitoneally injected (for buspirone) daily for 5 days. Normal control group (NC), not exposed to IS, was treated with $1 \%$ maltose instead of test agents. Hippocampal p65, p-p65, CREB, p-CREB, BDNF, and $\beta$-actin were analyzed by immunoblotting. Blood IL-6, corticosterone, and LPS were assayed by ELISA kits. Iba $1^{+}$and $\mathrm{LPS}^{+} / \mathrm{CD} 11 \mathrm{~b}^{+}$cells were measured using a confocal microscope. Data values were indicated as mean $\pm \operatorname{SEM}(n=7)$. ${ }^{\#} p<0.05$ vs. NC group. ${ }^{*} p<0.05$ vs. IS alone treated group.

(A)

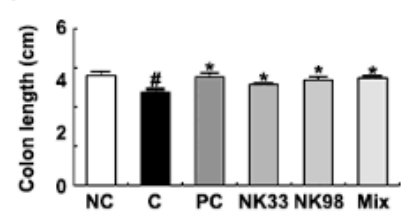

(D)

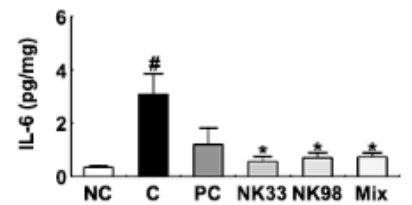

(G)

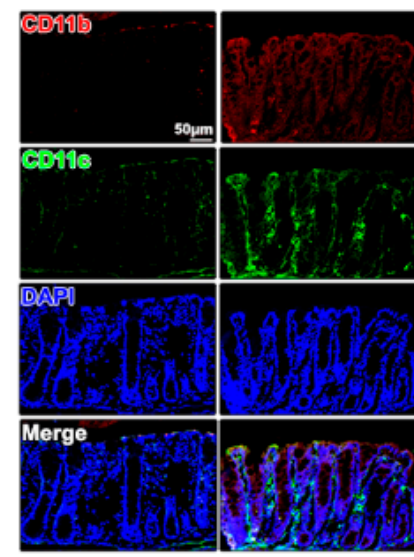

NC

(H)

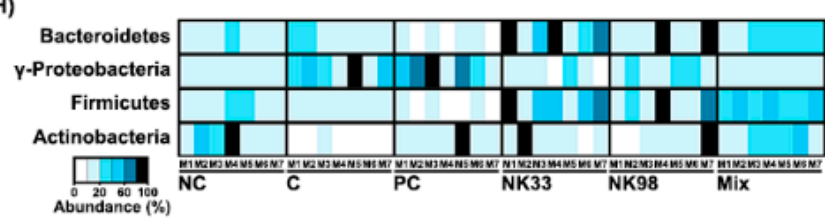

(B)

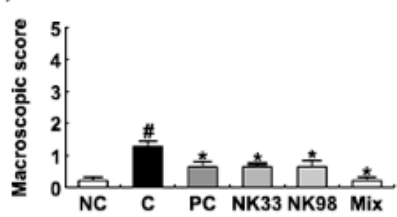

(E)

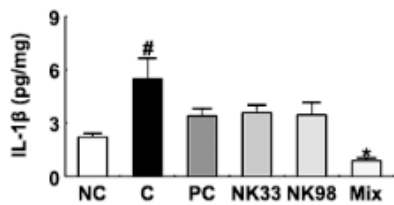

(C)

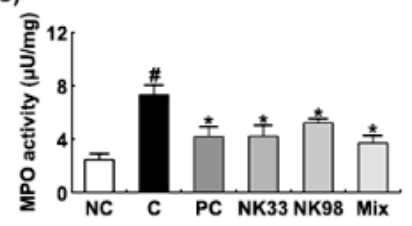

(F)
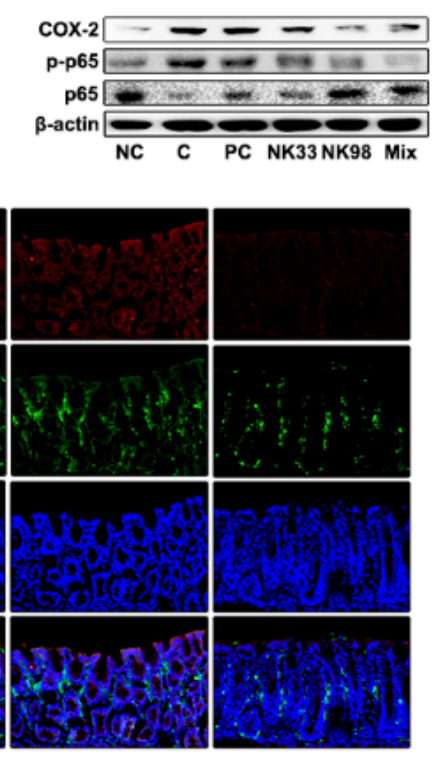

NK98

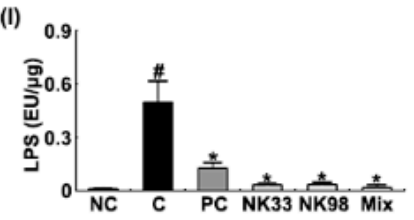

Figure 3. Oral administration of Lactobacillus reuteri NK33 and/or Bifidobacterium adolescentis NK98 alleviated immobilization stress (IS)-induced colitis in mice. Effects on the colon length (A), macroscopic score (B), myeloperoxidase (MPO) activity (C), IL-6 (D), IL-1 $\beta$ (E), and COX-2 expression, and NF- $\mathrm{kB}$ activation $(\mathbf{F})$. Effects on the infiltration of $\mathrm{CD} 11 \mathrm{~b}^{+} / \mathrm{CD} 11 \mathrm{c}^{+}$cells into the colon $(\mathbf{G})$, fecal microbiota composition (H), and fecal LPS levels (I). First, mice were exposed to IS and test agents (C, vehicle [1\% maltose]; NK33, $1 \times 10^{9} \mathrm{CFU} /$ mouse/day of NK33; NK98, $1 \times 10^{9} \mathrm{CFU} / \mathrm{mouse} /$ day of NK33; Mix, $1 \times 10^{9} \mathrm{CFU} / \mathrm{mouse} /$ day of the (1:1) mixture of NK33 and NK98]; and PC, $1 \mathrm{mg} / \mathrm{kg} /$ day of buspirone) were gavaged (for vehicle, NK33, and NK98) or intraperitoneally injected (for buspirone) daily for 5 days. Normal control group (NC), not exposed to IS, was treated with $1 \%$ maltose instead of test agents. Colonic p65, p-p65, COX-2, and $\beta$-actin were analyzed by immunoblotting. CD11b ${ }^{+}$and $\mathrm{CD}_{11} \mathrm{c}^{+}$cell populations were assayed using a confocal microscope. Fecal bacteria were assayed by qPCR. Fecal LPS assayed by ELISA kit. Data values are indicated as mean $\pm \operatorname{SEM}(n=7) .{ }^{*} p<0.05$ vs. NC group. ${ }^{*} p<0.05$ vs. IS group. 


\subsection{The Preventive Effects of NK33 and NK98 on IS-Induced Anxiety/Depression in Mice}

Next, to evaluate the preventive effects of NK33, NK98, or Mix on IS-induced anxiety/depression, we orally administered probiotics daily for 5 days, then exposed IS, and examined their effects on the occurrence and development of anxiety/depression and colitis in mice (Figure 4). Exposure to IS significantly decreased OT and OE during the elevated plus maze task to $37.7 \%[F(1,12)=25.676$, $p<0.001]$ and $69.0 \%[\mathrm{~F}(1,12)=10.090, p<0.05]$ of control mice, respectively (Figure 4A,B). Exposure of mice to IS also significantly suppressed TL and NT in the light/dark transition task and increased immobility in tail suspension and forced swimming tasks (Figure 4C-E). However, pretreatment with NK33 or NK98 prevented the occurrence of anxiety/depression: They significantly prevented OT in the elevated plus maze task to $73.0 \%[\mathrm{~F}(1,12)=10.982, p<0.05]$ and $86.5 \%[\mathrm{~F}(1,12)=16.004$, $p<0.05]$ of control mice, respectively, OE in the elevated plus maze task to $105.0 \%[\mathrm{~F}(1,12)=28.477$, $p<0.001]$ and $97.2 \%[\mathrm{~F}(1,12)=36.363, p<0.001]$ of control mice, respectively, TL in the light/dark transition task to $95.2 \%[\mathrm{~F}(1,12)=20.158, p<0.05]$ and $92.3 \%[\mathrm{~F}(1,12)=16.979, p<0.05]$ of control mice, respectively, NT in the light/dark transition task to $82.1 \%[\mathrm{~F}(1,12)=9.757, p<0.05]$ and $78.6 \%$ $[\mathrm{F}(1,12)=5.154, p<0.05]$ of control mice, respectively. NK33 and NK98 reduced immobility in the forced swimming task to $71.9 \%[\mathrm{~F}(1,12)=7.944, p<0.05]$ and $59.4 \%[\mathrm{~F}(1,12)=15.222, p<0.05]$ of mice treated with IS alone, respectively, and immobility in the tail suspension task to $72.9 \%[\mathrm{~F}(1,12)=4.578$, $p=0.054]$ and $69.6 \%[\mathrm{~F}(1,12)=4.5613, p=0.054]$ of mice treated with IS alone, respectively. IS exposure suppressed BDNF expression and CREB phosphorylation in the hippocampus and induced NF- $\mathrm{K}$ activation (Figure 4F). IS exposure also increased the infiltration of activated microglial cells into the hippocampus: It increased $\mathrm{Iba}^{+}$and $\mathrm{LPS}^{+} / \mathrm{CD} 11 \mathrm{~b}^{+}$cells in the brain (Figure $4 \mathrm{G}, \mathrm{H}$ ). However, oral administration of NK33, NK98, or Mix protected the suppression of BDNF expression, the induction of NF- $\kappa$ B activation, and the infiltration of $\mathrm{Iba}^{+}$and $\mathrm{LPS}^{+} / \mathrm{CD} 11 \mathrm{~b}^{+}$cells (activated microglial cells) by IS exposure. IS exposure also increased corticosterone, IL-6, and LPS levels in the blood of mice (Figure 4I-K). However, pretreatment with NK33, NK98, or Mix significantly protected the induction of corticosterone, IL-6, and LPS levels by IS exposure.

Exposure to IS alone significantly caused colitis: It induced colon shortening, colonic myeloperoxidase activity, proinflammatory cytokine IL-6 and IL-1 $\beta$ expression, and NF- $\kappa$ B activation, and COX-2 expression (Figure 5A-F). IS treatment also increased the CD11b ${ }^{+}$and/or CD11c ${ }^{+}$cell infiltration into the colon (Figure 5G). However, pretreatment with NK33, NK98, or Mix significantly prevented the IS-inducible colon shortening, macroscopic score, myeloperoxidase activity, IL-6 and COX-2 expression, and NF- $\mathrm{kB}$ activation, and $\mathrm{CD}_{11 b^{+}}$and/or CD11 ${ }^{+}$cell infiltration into the colon.

Furthermore, IS exposure increased the Proteobacteria population and reduced the Firmicutes and Actinobacteria populations in the feces (Figure 5H). However, pretreatment with NK33, NK98, or Mix protected the reduction of Firmicutes and Actinobacteria populations by IS exposure and suppressed the increase of the Proteobacteria population by IS exposure. Furthermore, they protected the IS-inducible fecal LPS production (Figure 5I). 
(A)

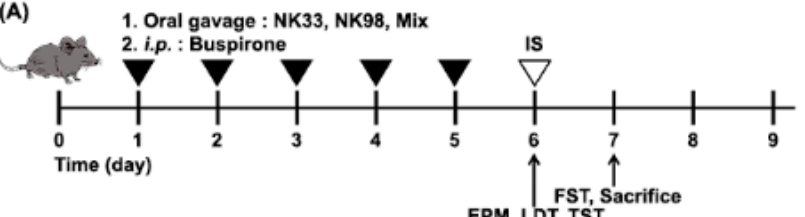

EPM, LDT, TST

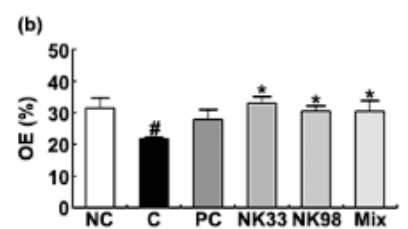

(D)

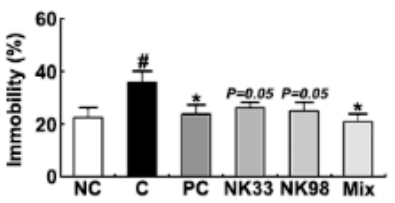

(G)

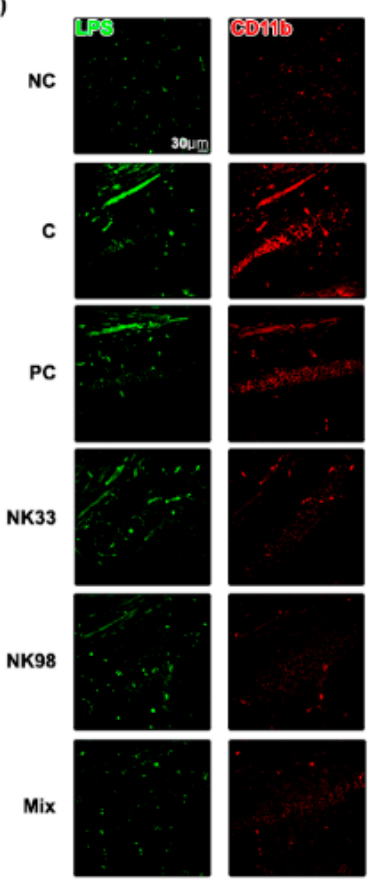

(l)

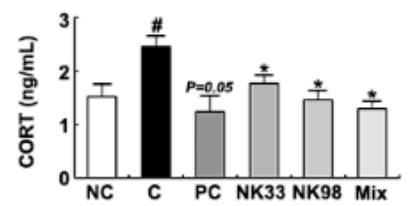

(C)

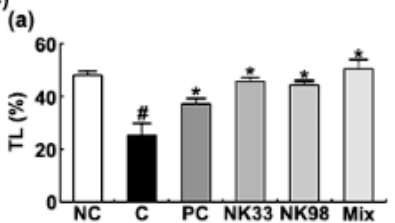

(E)

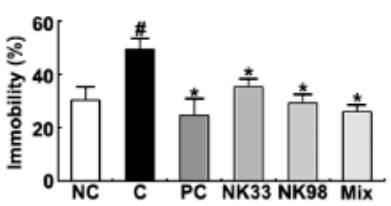

(H)
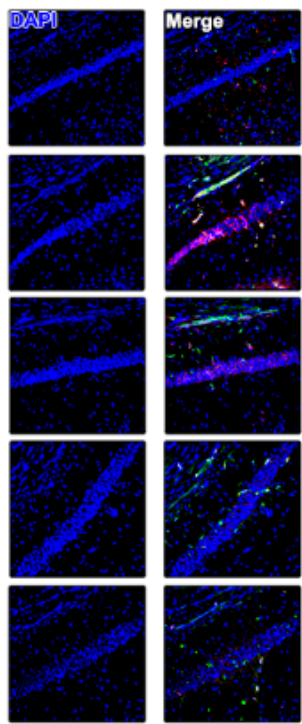

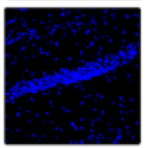

(J)
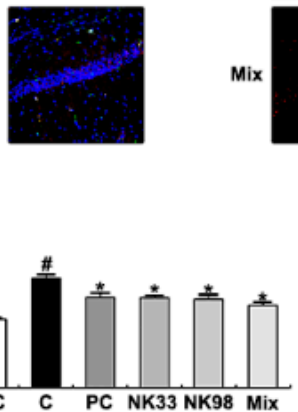

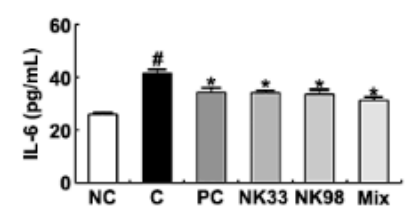

(B)

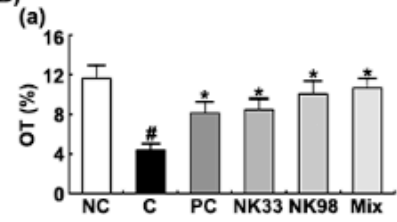

(b)

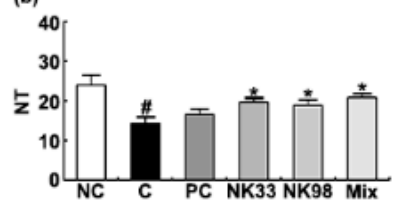

(F)

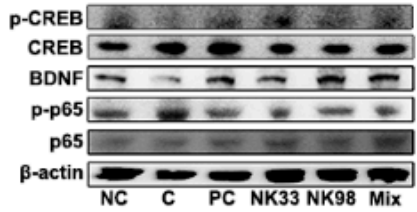

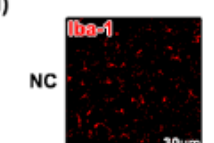
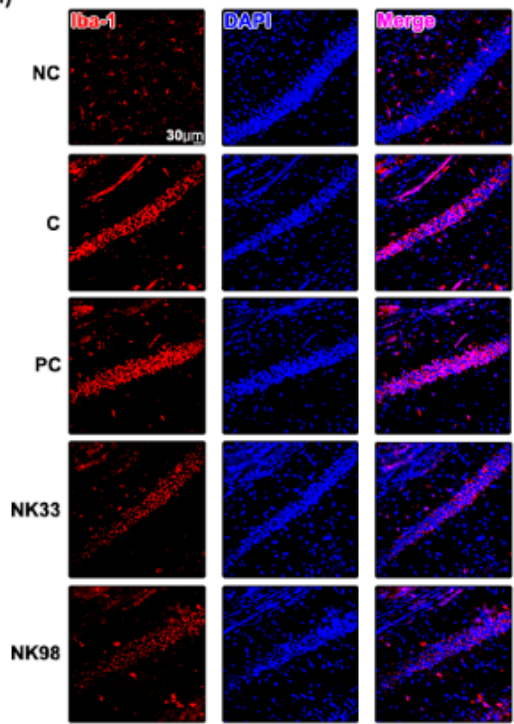
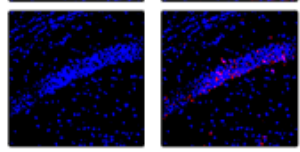

(K)

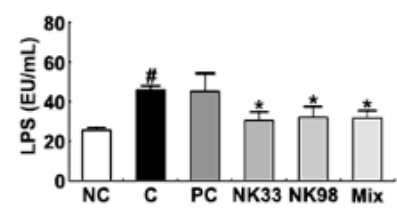

Figure 4. Pretreatment with Lactobacillus reuteri NK33 and/or Bifidobacterium adolescentis NK98 protected IS-induced anxiety and hippocampal inflammation in mice. (A) Procedure. Effects on anxiety-like behaviors in elevated plus maze (B: (a), OT; (b), OE), LDT (C: (a), TL; (b), NT), tail suspension (D), and forced swimming (E) tasks. (F) Effects on hippocampal BDNF expression and CREB and NF-KB activation. Effects on the infiltration of $\mathrm{LPS}^{+} / \mathrm{CD}_{11 b} \mathrm{~b}^{+}(\mathrm{G})$ and Iba ${ }^{+}$cells $(\mathbf{H})$ into the hippocampus. Effects on blood corticoterone (CORT, I), IL-6 (J), and LPS levels (K). Test agents (C, vehicle [1\% maltose]; NK33, $1 \times 10^{9} \mathrm{CFU} /$ mouse/day of NK33; NK98, $1 \times 10^{9} \mathrm{CFU} /$ mouse/day of NK33; Mix, $1 \times 10^{9} \mathrm{CFU} / \mathrm{mouse} /$ day of the (1:1) mixture of NK33 and NK98]; and PC, $1 \mathrm{mg} / \mathrm{kg} /$ day of buspirone) were gavaged (for vehicle, 
NK33, and NK98) or intraperitoneally injected (for buspirone) daily for 5 days and IS then exposed to mice. Normal control group (NC), not exposed to IS, were treated with $1 \%$ maltose instead of test agents. Hippocampal p65, p-p65, CREB, p-CREB, BDNF, and $\beta$-actin were assayed by immunoblotting. Blood corticosterone, IL- 6 , and LPS were assayed by ELISA kits. Iba1 ${ }^{+}$and $\mathrm{LPS}^{+} / \mathrm{CD}_{11 b^{+}}$cells were measured using a confocal microscope. Data values are indicated as mean $\pm \operatorname{SEM}(n=7) .{ }^{*} p<0.05$ vs. NC group. ${ }^{*} p<0.05$ vs. IS group.

(A)

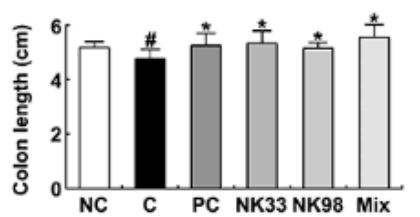

(D)

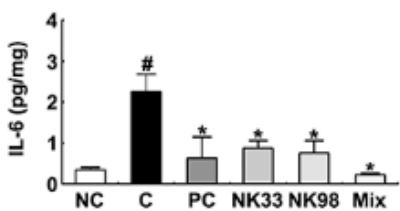

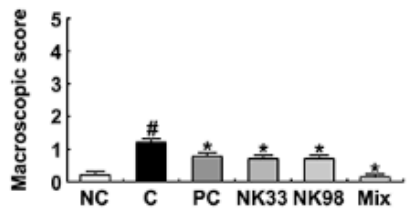

(E)

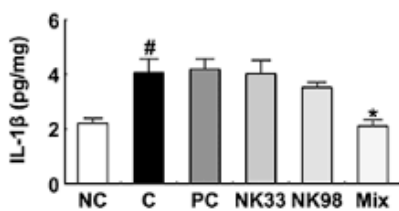

(C)

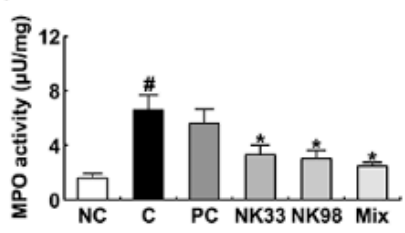

(F)

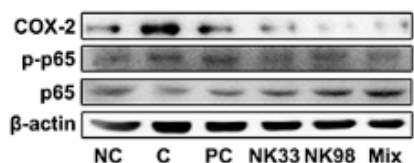

(G)

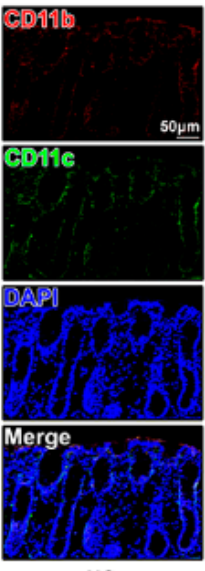

NC

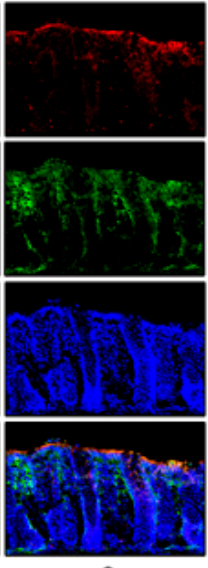

c

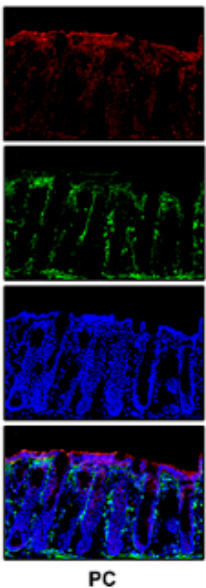

PC

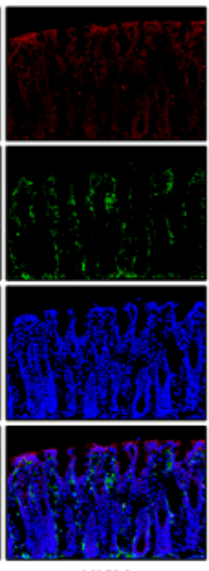

NK33

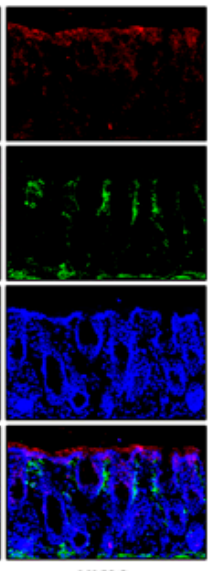

NK98

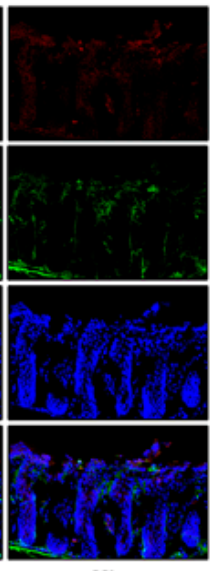

Mix
(H)

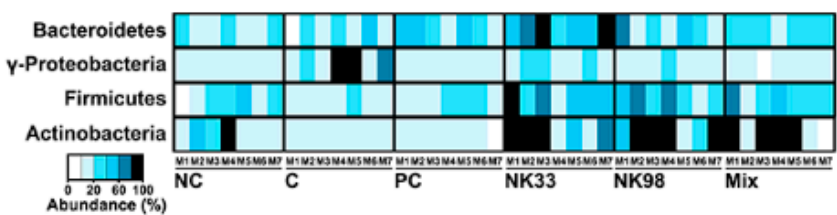

(I)

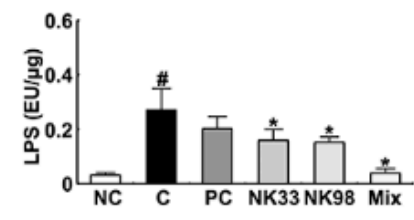

Figure 5. Pretreatment with Lactobacillus reuteri NK33 and/or Bifidobacterium adolescentis NK98 protected IS-induced colitis in mice. Effects on colon length (A), macroscopic score (B), colonic myeloperoxidase (MPO) activity (C), IL-6 (D), IL-1 $\beta$ (E), and COX-2 expression and NF- $\kappa$ B activation (F). (G) Effects on

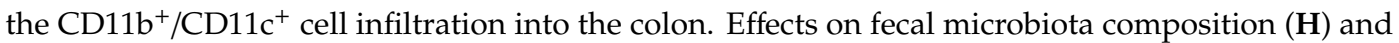
fecal LPS levels (I). Test agents (C, vehicle [1\% maltose]; NK33, $1 \times 10^{9} \mathrm{CFU} / \mathrm{mouse} /$ day of NK33; NK98, $1 \times 10^{9} \mathrm{CFU} / \mathrm{mouse} /$ day of NK33; Mix, $1 \times 10^{9} \mathrm{CFU} / \mathrm{mouse} /$ day of the (1:1) mixture of NK33 and NK98]; and PC, $1 \mathrm{mg} / \mathrm{kg} /$ day of buspirone) were gavaged (for vehicle, NK33, and NK98) or intraperitoneally injected (for buspirone) daily for 5 days and IS then exposed to mice. Normal control group (NC), not exposed to IS, were treated with $1 \%$ maltose instead of test agents. Colonic p65, p-p65, COX-2, and $\beta$-actin were analyzed by immunoblotting. $C D 11 b^{+}$and CD11 ${ }^{+}$cells were assayed using a confocal microscope. Fecal bacteria were assayed by qPCR. Fecal LPS were assayed by ELISA kit. Data values are indicated as mean $\pm \operatorname{SEM}(n=7) .{ }^{\#} p<0.05$ vs. NC group. ${ }^{*} p<0.05$ vs. IS group. 


\subsection{NK33 and NK98 Induced BDNF Expression and CREB Phosphorylation in LPS-Stimulated SH-SY5Y Cells}

Next, we examined whether NK33 and NK98 could induce CREB phosphorylation and BDNF expression in LPS-stimulated SH-SY5Y cells (Figure 6). NK33 and NK98 potently increased LPS-suppressed CREB phosphorylation as well as BDNF expression.

(A)

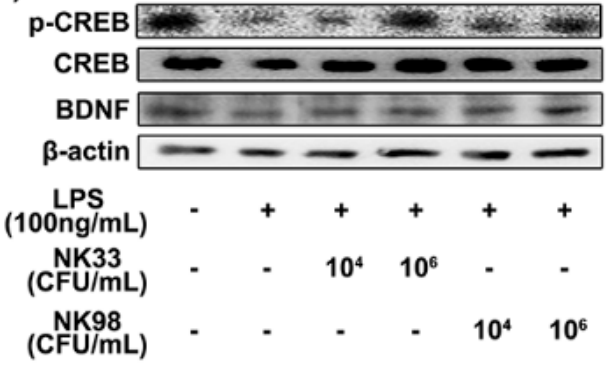

(B)
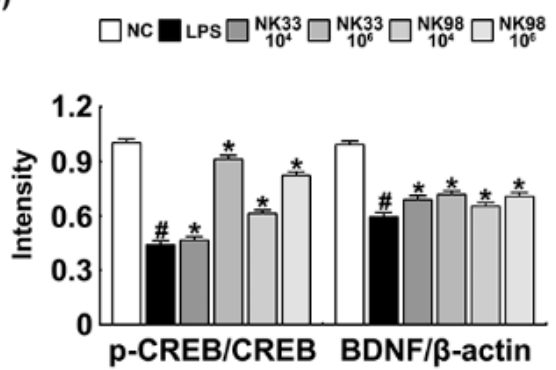

Figure 6. Effect of Lactobacillus reuteri NK33 and Bifidobacterium adolescentis NK98 on BDNF expression (A) and CREB activation in LPS-stimulated SH-SY5Y cells $\left(\right.$ B). Cells $\left(1 \times 10^{6}\right)$ were treated with LPS in the absence or presence of NK33 or NK98 $\left(1 \times 10^{4}\right.$ or $\left.1 \times 10^{6} \mathrm{CFU} / \mathrm{mL}\right)$ for $20 \mathrm{~h}$. NC was treated with vehicle alone. $B D N F, C R E B, p-C R E B$, and $\beta$-actin were measured by immunoblotting. Data values are indicated as mean $\pm \operatorname{SEM}(n=4)$. ${ }^{\#} p<0.05$ vs. group not treated with LPS; ${ }^{*} p<0.05$ vs. LPS alone treated group.

\section{Discussion}

The intolerable exposure to stressors such as immobilization disrupts the gut immune system and microbiota composition through the HPA axis, leading to the occurrence of gut inflammation and psychiatric disorders $[4,25,32]$. The exposure to stressors increases the occurrence of anxiety in germ-free or antibiotic-treated mice more sensitively than in specific pathogen-free mice with gut microbiota $[18,25,33]$. The fecal transplantation of SPF mice into germ-free mice reduces the occurrence of anxiety [19]. First, stressor exposure induces TNF- $\alpha$ and IL-6 expression in the brain, blood, and intestine with the secretion of adrenaline, noradrenaline, and glucocorticoids from the adrenal gland, leading to the increased gut membrane permeability with gut inflammation [25,34]. Second, it increases the Proteobacteria population in the gut microbiota composition and gut bacterial LPS production $[25,35,36]$. The disruption of gut microbiota and membrane permeability by stressors elevates the blood LPS level [30]. The excessive exposure to LPS induces TNF- $\alpha$ expression in the brain and suppresses BDNF expression, leading to the occurrence of anxiety/depression $[37,38]$.

In the present study, we found that the exposure of mice to IS caused psychiatric disorders, anxiety and depression, hippocampal inflammation, and gut microbiota dysbiosis. Oral administration of NK33 and/or NK98 significantly suppressed the IS-induced Proteobacteria population and gut bacterial LPS production. Their treatments also alleviated colitis: They inhibited IS-induced colon shortening, myeloperoxidase activity, and macrophage and DC infiltration into the gastrointestinal tract. Furthermore, they suppressed blood LPS levels. Jang et al. also reported that IS exposure suppressed gut tight junction protein expression in the gut and brain and increased blood LPS levels by increasing gut membrane permeability [30]. These results suggest that NK33 and NK98 can reduce blood LPS levels by suppressing gut permeability through the inhibition of gut inflammation and bacterial LPS production.

NK33 and NK98 also lowered IS-induced blood IL-6 and corticosterone levels in mice. They reduced IS-induced Iba1+ and $\mathrm{LPS}^{+} / \mathrm{CD} 11 \mathrm{~b}^{+}$cell (activated microglia) populations in the hippocampus. Oh et al. reported that the suppression of IL-6 expression by phytochemicals induced the attenuation of anxiety in mice [39]. Corticosterone, IL-6, and TNF- $\alpha$ were highly expressed in patients with anxiety/depression [40-42]. These results suggest that NK33 and NK98 can inhibit the activation of the HPA axis, which stimulates the secretion of adrenocorticotrophin and corticosterone from 
the adrenal gland and proinflammatory cytokine IL- 6 and TNF- $\alpha$ from immune cells. Furthermore, we found that NK33 and NK98 induced BDNF expression and suppressed NF- $\mathrm{kB}$ activation in the hippocampus. They potently suppressed IS-induced anxiety/depression-like behaviors. Lee et al. reported that the exposure to LPS suppressed NF-kB-mediated BDNF expression in the hippocampus [27]. NK33 and NK98 inhibited NF-KB in LPS-induced BV-2 cells and increased BDNF expression in LPS-stimulated SH-SY5Y cells. These results suggest that NK33 and NK98 alleviated the suppression of NF-kB-mediated BDNF expression in the hippocampus with the regulation of LPS infiltration into the brain, resulting in the attenuation of anxiety and depression.

Moreover, the disruption of gut microbiota by IS exposure resulted in gut inflammation as well as anxiety/depression. NK33 and NK98 alleviated IS-induced anxiety and depression with the suppression of gut inflammation and microbiota disruption. Moreover, they reduced IL-6, TNF- $\alpha$, and corticosterone levels, suppressed NF- $\mathrm{kB}$ activation in the colon and blood, and induced BDNF expression in the hippocampus. Lactobacillus plantarum, Bifidobacterium longum NCC3001, and Bifidobacterium infantis suppress anxiety-like behavior by restoring noradrenaline levels, inducing GABA production, or protecting gut dysbiosis, respectively $[24,43,44]$. Bifidobacterium adolescentis IM38, a human gut bacterium, inhibits IS-induced anxiety by regulating the $\mathrm{GABA}_{\mathrm{A}}$ receptor [26]. Lactobacillus johnsonii, a commensal gut bacterium of mice, suppresses anxiety in IS-exposed mice by inhibiting gut bacterial LPS production [35]. Lactobacillus rhamnosus HN001 reduced depression and anxiety in the postpartum period of women [45]. Lactobacillus helveticus NS8 also improves depression-like behaviors in chronic restraint stress-exposed rats [46]. The gut microbiota is bidirectionally connected to the brain: Dysfunction of the HPA axis by stressors can cause gut microbiota dysbiosis and psychiatric disorders and probiotics can alleviate anxiety $[47,48]$. These results suggest that probiotics can alleviate anxiety and depression by suppressing gut dysbiosis.

\section{Conclusions}

NK33 and NK98 additively or synergistically prevented and alleviated anxiety and depression by alleviating gut dysbiosis through the suppression of the Proteobacteria population and gut microbiota LPS production.

Author Contributions: D.-H.K. conceived the idea for this study. H.-M.J. and D.-H.K. designed the experiment. H.-M.J. and K.-E.L. performed the experiment. H.-M.J., K.-E.L., and D.-H.K. analyzed the data. H.-M.J., K.-E.L., and D.-H.K. wrote the main manuscript text. All authors reviewed and approved the contents of the manuscript.

Funding: This work was supported by the Medical Research Program (2017R1A5A2014768) through the National Research Foundation of Korea (NRF) funded by the Ministry of Science and ICT.

Conflicts of Interest: The authors declare no conflicts of interest. The funders had no role in the design of the study, in the collection, analyses, or interpretation of data, in the writing of the manuscript, or in the decision to publish the results.

\section{References}

1. Baxter, A.J.; Scott, K.M.; Ferrari, A.J.; Norman, R.E.; Vos, T.; Whiteford, H.A. Challenging the myth of an "epidemic" of common mental disorders: Trends in the global prevalence of anxiety and depression between 1990 and 2010. Depress Anxiety 2014, 31, 506-516. [CrossRef]

2. Bandelow, B.; Michaelis, S. Epidemiology of anxiety disorders in the 21st century. Dialogues Clin. Neurosci. 2015, 17, 327-335. [PubMed]

3. Weger, M.; Sandi, C. High anxiety trait: A vulnerable phenotype for stress-induced depression. Neurosci. Biobehav. Rev. 2018, 87, 27-37. [CrossRef]

4. Jaggi, A.S.; Bhatia, N.; Kumar, N.; Singh, N.; Anand, P.; Dhawan, R. A review on animal models for screening potential anti-stress agents. J. Neurol. Sci. 2011, 32, 993-1005. [CrossRef] [PubMed]

5. Sutanto, D.; Kloet, E.R. The use of various animal models in the study of stress and stress-related phenomena. Lab. Anim. 1994, 28, 293-306. [CrossRef] 
6. Haddad, J.J.; Saade, N.E.; Safieh-Garabedian, B. Cytokines and neuro-immune-endocrine interactions: A role for the hypothalamic-pituitary-adrenal revolving axis. J. Neuroimmunol. 2002, 133, 1-19. [CrossRef]

7. Foster, J.A. Gut microbiome and behavior: Focus on neuroimmune interactions. Int. Rev. Neurobiol. 2016, 131, 49-65. [PubMed]

8. Xie, Z.M.; Wang, X.M.; Xu, N.; Wang, J.; Pan, W.; Tang, X.H.; Zhou, Z.Q.; Hashimoto, K.; Yang, J.J. Alterations in the inflammatory cytokines and brain-derived neurotrophic factor contribute to depression-like phenotype after spared nerve injury: Improvement by ketamine. Sci. Rep. 2017, 7, 3124. [CrossRef]

9. Şahin, T.D.; Karson, A.; Balcı, F.; Yazır, Y.; Bayramgürler, D.; Utkan, T. TNF- $\alpha$ inhibition prevents cognitive decline and maintains hippocampal BDNF levels in the unpredictable chronic mild stress rat model of depression. Behav. Brain Res. 2015, 292, 233-240. [CrossRef]

10. Libertucci, J.; Young, V.B. The role of the microbiota in infectious diseases. Nat. Microbiol. 2019, 4, 35-45. [CrossRef]

11. Broecker, F.; Russo, G.; Klumpp, J.; Moelling, K. Stable core virome despite variable microbiome after fecal transfer. Gut Microbes 2017, 8, 214-220. [CrossRef]

12. Flint, H.J.; Scott, K.P.; Louis, P.; Duncan, S.H. The role of the gut microbiota in nutrition and health. Nat. Rev. Gastroenterol. Hepatol. 2012, 9, 577-589. [CrossRef]

13. Bäckhed, F.; Ley, R.E.; Sonnenburg, J.L.; Peterson, D.A.; Gordon, J.I. Host-bacterial mutualism in the human intestine. Science 2005, 307, 1915-1920. [CrossRef]

14. Gill, S.R.; Pop, M.; Deboy, R.T.; Eckburg, P.B.; Turnbaugh, P.J.; Samuel, B.S.; Gordon, J.I.; Relman, D.A.; Fraser-Liggett, C.M.; Nelson, K.E. Metagenomic analysis of the human distal gut microbiome. Science 2006, 312, 1355-1359. [CrossRef]

15. Chow, J.; Lee, S.M.; Shen, Y.; Khosravi, A.; Mazmanian, S.K. Host-bacterial symbiosis in health and disease. Adv. Immunol. 2010, 107, 243-274.

16. Carabotti, M.; Scirocco, A.; Maselli, M.A.; Severi, C. The gut-brain axis: Interactions between enteric microbiota, central and enteric nervous systems. Ann. Gastroenterol. 2015, 28, 203-209.

17. Mackos, A.R.; Varaljay, V.A.; Maltz, R.; Gur, T.L.; Bailey, M.T. Role of the intestinal microbiota in host responses to stressor exposure. Int. Rev. Neurobiol. 2016, 131, 1-19.

18. Crumeyrolle-Arias, M.; Jaglin, M.; Bruneau, A.; Vancassel, S.; Cardona, A.; Daugé, V.; Naudon, L.; Rabot, S. Absence of the gut microbiota enhances anxiety-like behavior and neuroendocrine response to acute stress in rats. Psychoneuroendocrinology 2014, 42, 207-217. [CrossRef]

19. Sudo, N.; Chida, Y.; Aiba, Y.; Sonoda, J.; Oyama, N.; Yu, X.N.; Kubo, C.; Koga, Y. Postnatal microbial colonization programs the hypothalamic-pituitary-adrenal system for stress response in mice. J. Physiol. 2004, 558, 263-275. [CrossRef]

20. Belda, X.; Fuentes, S.; Daviu, N.; Nadal, R.; Armario, A. Stress-induced sensitization: The hypothalamic-pituitary-adrenal axis and beyond. Stress 2015, 18, 269-279. [CrossRef]

21. Malan-Muller, S.; Valles-Colomer, M.; Raes, J.; Lowry, C.A.; Seedat, S.; Hemmings, S.M.J. The gut microbiome and mental health: Implications for anxiety- and trauma-related disorders. OMICS 2018, 22, 90-107. [CrossRef]

22. Plaza-Diaz, J.; Ruiz-Ojeda, F.J.; Gil-Campos, M.; Gil, A. Mechanisms of action of probiotics. Adv. Nutr. 2019, 10 (Suppl. 1), S49-S66. [CrossRef]

23. Liu, X.; Cao, S.; Zhang, X. Modulation of gut microbiota-brain axis by probiotics, prebiotics, and diet. J. Agric. Food Chem. 2015, 63, 7885-7895. [CrossRef]

24. Davis, D.J.; Doerr, H.M.; Grzelak, A.K.; Busi, S.B.; Jasarevic, E.; Ericsson, A.C.; Bryda, E.C. Lactobacillus plantarum attenuates anxiety-related behavior and protects against stress-induced dysbiosis in adult zebrafish. Sci. Rep. 2016, 6, 33726. [CrossRef]

25. Jang, H.M.; Lee, H.J.; Jang, S.E.; Han, M.J.; Kim, D.H. Evidence for interplay among antibacterial-induced gut microbiota disturbance, neuro-inflammation, and anxiety in mice. Mucosal Immunol. 2018, 11, 1386-1397. [CrossRef]

26. Jang, H.M.; Jang, S.E.; Han, M.J.; Kim, D.H. Anxiolytic-like effect of Bifidobacterium adolescentis IM38 in mice with or without immobilisation stress. Benef. Microbes 2018, 9, 123-132. [CrossRef] 
27. Lee, H.J.; Lim, S.M.; Ko, D.B.; Jeong, J.J.; Hwang, Y.H.; Kim, D.H. Soyasapogenol B and genistein attenuate lipopolysaccharide-induced memory impairment in mice by the modulation of NF- $\mathrm{B}$-Mediated BDNF expression. J. Agric. Food Chem. 2017, 65, 6877-6885. [CrossRef]

28. Chu, X.; Zhou, Y.; Hu, Z.; Lou, J.; Song, W.; Li, J.; Liang, X.; Chen, C.; Wang, S.; Yang, B.; et al. 24-Hour-restraint stress induces long-term depressive-like phenotypes in mice. Sci. Rep. 2016, 9, 6:32935. [CrossRef]

29. Dunn, A.J.; Swiergiel, A.H. Effects of interleukin-1 and endotoxin in the forced swim and tail suspension tests in mice. Pharmacol. Biochem. Behav. 2005, 81, 688-693. [CrossRef]

30. Jang, S.E.; Lim, S.M.; Jeong, J.J.; Jang, H.M.; Lee, H.J.; Han, M.J.; Kim, D.H. Gastrointestinal inflammation by gut microbiota disturbance induces memory impairment in mice. Mucosal Immunol. 2018, 11, 369-379. [CrossRef]

31. Kim, K.A.; Gu, W.; Lee, I.A.; Joh, E.H.; Kim, D.H. High fat diet-induced gut microbiota exacerbates inflammation and obesity in mice via the TLR4 signaling pathway. PLoS ONE 2012, 7, e47713. [CrossRef]

32. Ait-Belgnaoui, A.; Durand, H.; Cartier, C.; Chaumaz, G.; Eutamene, H.; Ferrier, L.; Houdeau, E.; Fioramonti, J.; Bueno, L.; Theodorou, V. Prevention of gut leakiness by a probiotic treatment leads to attenuated HPA response to an acute psychological stress in rats. Psychoneuroendocrinology 2012, 37, 1885-1895. [CrossRef]

33. Bercik, P.; Collins, S.M. The effects of inflammation, infection and antibiotics on the microbiota-gut-brain axis. Adv. Exp. Med. Biol. 2014, 817, 279-289.

34. Serrats, J.; Grigoleit, J.S.; Alvarez-Salas, E.; Sawchenko, P.E. Pro-inflammatory immune-to-brain signaling is involved in neuroendocrine responses to acute emotional stress. Brain Behav. Immun. 2017, 62, 53-63. [CrossRef]

35. Jang, H.M.; Lee, K.E.; Lee, H.J.; Kim, D.H. Immobilization stress-induced Escherichia coli causes anxiety by inducing NF-kB activation through gut microbiota disturbance. Sci. Rep. 2018, 8, 13897. [CrossRef]

36. Campos, A.C.; Rocha, N.P.; Nicoli, J.R.; Vieira, L.Q.; Teixeira, M.M.; Teixeira, A.L. Absence of gut microbiota influences lipopolysaccharide-induced behavioral changes in mice. Behav. Brain Res. 2016, 312, 186-194. [CrossRef]

37. Jeong, M.Y.; Jang, H.M.; Kim, D.H. High-fat diet causes psychiatric disorders in mice by increasing Proteobacteria population. Neurosci. Lett. 2019, 698, 51-57. [CrossRef]

38. Tanaka, S.; Ide, M.; Shibutani, T.; Ohtaki, H.; Numazawa, S.; Shioda, S.; Yoshida, T. Lipopolysaccharide-induced microglial activation induces learning and memory deficits without neuronal cell death in rats. J. Neurosci. Res. 2006, 83, 557-566. [CrossRef]

39. Oh, H.A.; Kim, D.E.; Choi, H.J.; Kim, N.J.; Kim, D.H. Anti-stress effects of 20(S)-protopanaxadiol and 20(S)-protopanaxatriol in immobilized mice. Biol. Pharm. Bull. 2015, 38, 331-335. [CrossRef]

40. Amitai, M.; Taler, M.; Carmel, M.; Michaelovsky, E.; Eilat, T.; Yablonski, M.; Orpaz, N.; Chen, A.; Apter, A.; Weizman, A.; et al. The relationship between plasma cytokine levels and response to selective serotonin reuptake inhibitor treatment in children and adolescents with depression and/or anxiety disorders. J. Child Adolesc. Psychopharmacol. 2016, 26, 727-732. [CrossRef]

41. Guo, L.; Ren, L.; Zhang, C. Relationship between depression and inflammatory factors and brain-derived neurotrophic factor in patients with perimenopause syndrome. Exp. Ther. Med. 2018, 15, 4436-4440. [CrossRef]

42. Ruzek, M.C.; Miller, A.H.; Opal, S.M.; Pearce, B.D.; Biron, C.A. Characterization of early cytokine responses and an interleukin (IL)-6-dependent pathway of endogenous glucocorticoid induction during murine cytomegalovirus infection. J. Exp. Med. 1997, 185, 1185-1192. [CrossRef]

43. Bercik, P.; Park, A.J.; Sinclair, D.; Khoshdel, A.; Lu, J.; Huang, X.; Deng, Y.; Blennerhassett, P.A.; Fahnestock, M.; Moine, D.; et al. The anxiolytic effect of Bifidobacterium longum NCC3001 involves vagal pathways for gut-brain communication. Neurogastroenterol. Motil. 2011, 23, 1132-1139. [CrossRef]

44. Desbonnet, L.; Garrett, L.; Clarke, G.; Kiely, B.; Cryan, J.F.; Dinan, T.G. Effects of the probiotic Bifidobacterium infantis in the maternal separation model of depression. Neuroscience 2010, 170, 1179-1188. [CrossRef]

45. Slykerman, R.F.; Hood, F.; Wickens, K.; Thompson, J.M.D.; Barthow, C.; Murphy, R.; Kang, J.; Rowden, J.; Stone, P.; Crane, J.; et al. Probiotic in Pregnancy Study Group. Effect of Lactobacillus rhamnosus HN001 in pregnancy on postpartum symptoms of depression and anxiety: A randomised double-blind placebo-controlled trial. EBioMedicine 2017, 24, 159-165. [CrossRef] 
46. Liang, S.; Wang, T.; Hu, X.; Luo, J.; Li, W.; Wu, X.; Duan, Y.; Jin, F. Administration of Lactobacillus helveticus NS8 improves behavioral, cognitive, and biochemical aberrations caused by chronic restraint stress. Neuroscience 2015, 310, 561-577. [CrossRef]

47. Foster, J.A.; McVey Neufeld, K.A. Gut-brain axis: How the microbiome influences anxiety and depression. Trends Neurosci. 2013, 36, 305-312. [CrossRef]

48. Petra, A.I.; Panagiotidou, S.; Hatziagelaki, E.; Stewart, J.M.; Conti, P.; Theoharides, T.C. Gut-microbiota-brain axis and its effect on neuropsychiatric disorders with suspected immune dysregulation. Clin. Ther. 2015, 37, 984-995. [CrossRef]

(C) 2019 by the authors. Licensee MDPI, Basel, Switzerland. This article is an open access article distributed under the terms and conditions of the Creative Commons Attribution (CC BY) license (http://creativecommons.org/licenses/by/4.0/). 